\title{
RUMBLE IN THE JUNGLE City, Place and Uncanny Bass
}

\author{
$\bullet$ Feature Article $\longrightarrow$ \\ Chris Christodoulou \\ UNIVERSITY OF WESTMINSTER
}

\begin{abstract}
While bass powerfully resonates among the cultural discourses, lexicology and marketing of a range of electronic dance music (EDM) styles, little popular music scholarship has paid attention to the subjective, phenomenological and psychophysiological significance of bass in its modulation of intense feelings of pleasure. This article examines the linking in jungle/drum 'n' bass culture of bass as a sonic space that produces a powerful sense of jouissance where identity can seem to unravel on the dance floor and an articulation of contemporary urban space as a place of subjective loss and regression. Overlaying Freud's notion of the uncanny and Kristeva's signifying space of the chora, I discuss how this fetishisation of bass can be linked to the music's cultural formation from deindustrialised regions in London and the South-East of England during the early-1990s; its accelerated break-beats and "dark" bass-lines can be seen to inscribe recent rapid social, cultural and environmental transformations in the urban metropolis.
\end{abstract}

KEYWORDS: break-beat, city, drum 'n' bass, psychoanalysis, speed

Chris Christodoulou is a Lecturer in the School of Media, Arts and Design at the University of Westminster in London. His research is concerned with the relationship between speed, technology and urban experience in EDM scenes and subcultures. He completed his $\mathrm{PhD}$, entitled Renegade Hardware: Speed, Pleasure and Cultural Practice in Drum 'n' Bass Culture, undertaken at London South Bank University, in 2009.

Dancecult: Journal of Electronic Dance Music Culture 3(1): 44-63

ISSN 1947-5403 @2011 Dancecult http://dj.dancecult.net

DOI 10.12801/1947-5403.2011.03.01.03

dsencecult 
CWe've said all we can say and nobody listens anyway, so fuck 'em, we just give 'em bass!

-Goldie (in Toop 1995: 92)

\section{Introduction: Bass is the Place ${ }^{6}$}

THE POPULARITY of bass-oriented EDM styles like grime, dubstep and jungle/drum 'n' bass $^{7}$ in the UK points to a link between psychological experiences of low-frequency sound and culturally inscribed discourses and desires of urban life. The sonic dominance of bass is transmitted via the womb-like environment of dark, hot and sweaty metropolitan dance clubs, framing the city as unhomely home through the summoning of the infant child's primal memories of its original "home" within the mother's body. Given that the child's first exposure to sound is through its proximity to the mother's internal organs and a hearing range that is limited to low frequencies, it can be argued that bass partially reawakens both the pre-subjective state of comfortable bliss felt by the infant from inside the womb and the subjective collapse threatened by its failure to fully enter into subjectivity outside it. It is in this way that bass - often positively described by participants as being "dark" — can be seen to be a key sonic inscription for the uncanniness of urban space; the precariousness of the subject's positioning to the mother's bodily "home" is transferred onto the unhomeliness of contemporary urban space. The unstable conditions and frenetic pace of change of urban life seem to facilitate an intensified desire for bass-heavy music that stimulates primal memories of the rhythm of the mother's womb and the sound of her heartbeat.

I wish to discuss the genre as one prominent example of how bass articulates the postindustrial metropolis as both a "real" space-real, that is, in sociological, demographic and material terms-and one that is fetishised. In particular, the fast tempos of drum ' $n$ ' bass $^{8}$ music allow it to articulate specific experiences of living and growing up in a postindustrial society where speed is a dominant condition. ${ }^{9}$ This paper will hereby use the term "uncanny" in its psychoanalytic sense, as adopted by Anthony Vidler (1992); the unsettling slippage between a place that is home and unhomely was the basis for Freud's view that the uncanny (unheimlich) is rooted in the familiar (heimlich). This concept will be applied to the local contexts from which drum ' $n$ ' bass has developed, before being revisited through a focus on the experience of bass as a sonic space on the dance floor, and on its articulation of anxieties relating to the crisis of masculinity in the context of post-industrial socioeconomic transformations.

\section{THE URBAN UNCANNY}

ADAm F's seminal drum ' $\mathrm{n}$ ' bass track "Metropolis" (Metropolis, 1996) articulates a contemporary thematic framework regarding the post-industrial city, a theme inscribed in its title and in the period of its emergence. A derelict and dehumanised cityscape is suggested 
by the use of abstracted, un-naturalistic sounds, sinister chords and indecipherable distress calls; humans and other forms of natural life no longer seem to inhabit this space or are menacingly hidden from view. Blaring low-frequency bass stabs convey a sense of existing be-low, on or beneath the streets, where danger is ever-present. The pervasive menace generated by these deep rumblings is supplemented by familiar sounds like human voices and communications media in states of threatening unfamiliarity. Rhythmic events are punctuated by fragments of emergency broadcasts, distorted and reversed to sound ominous and confusing. The overall effect of this scenario is that the city is felt deeply within our physical beings, as though the metropolis resides in our inner selves. The urban is thereby doubly textured; it is a space that is concrete and "real", but also brutally fantastic.

A similar double positioning can be found in the classic science fiction film by Fritz Lang that inspired Adam F to produce the drum 'n' bass track of the same name. In the film Metropolis, workers beneath the city toil on gigantic machines and endless assembly lines. Hidden from view, the workforce takes on a primordial significance. The technology that serves to dehumanise the workers potentially serves as the basis for proletarian revolution; machine power can be harnessed to overthrow the capitalist class. The film redirects this power in terms of an unrestricted female sexuality, signified as a mechanical vamp that is built to lead the workers to rebellion and disaster (Huyssen 1982). Thereby, the metropolis as a double space containing a visible high or above-ground-the "rational" spaces of the established social order — and a hidden underground - the site of "irrational" and repressed energies-powerfully resonates in both Adam F's track and Lang's film.

Anthony Vidler applies a similar duality to the post-industrial cityscape in terms of its simultaneously modern and pre-modern character:

The contemporary sensibility that sees the uncanny erupt in empty parking lots around abandoned or run-down shopping malls ... that is, the wasted margins and surface appearances of postindustrial culture, this sensibility has its roots and draws its commonplaces from a long but essentially modern tradition (1992: 3).

For Vidler, the post-industrial city is a magical and enchanted space that is paradoxically rooted in modernity. Its uncanniness comes from both a rational network of social and economic priorities based on productivity and a site of the waste and the depletion of human and material resources. Vidler claims that the fear of darkened spaces and the density of the social marked Enlightenment conceptions of space; "it is in the intimate associations of the two, their uncanny ability to slip from one to the other, that the sublime as instrument of fear retains its hold - in that ambiguity that stages the presence of death in life, dark space in bright space" (1992: 172).

In defining post-industrial, post-Enlightenment urban space as "uncanny", Vidler draws on a Freudian psychoanalytic context to show how the city permeates the conscious and subconscious spaces of urban subjectivity. The urban uncanny can be further examined with reference to Sarah Kember's definition of the fetish (1995). By showing how the city is both a space onto which desire is projected, ${ }^{12}$ the uncanny city in drum ' $n$ ' bass culture will 
be shown to be a fetishised space. Kember argues that patriarchy combines the "female body with the fetish" to produce a "fantasy of unmediated access to reproduction and origin" (1995: 110). In Freudian psychoanalysis, a fetish is a sexual or non-sexual part of the body or an object that is invested with sexual energy. It is a substitute for the mother's penis that the little boy once believed in. The realisation that the mother does not have a penis gives rise to the child's sexual theory that she once possessed one and has been deprived of it, and to the male child's fear that he too might be castrated (Freud 2001). Thereby, it is possible to consider the fetishisation of any external space as "home" in terms of the projection of internal drives that emanate from the subject's desire to "complete" the mother's body and to recover a state of unity it once felt inside the womb. While the fetish allows for the denial of castration anxiety, for Kember, the fetish is re-read in terms of the female body, including her reproductive ability (1995: 110). In this way, the projection of feelings of homeliness onto external space involves a process of fetishisation that is inscribed by infantile memories of the mother's body as primary space.

Julia Kristeva (1980) focuses on the developmental significance of the infant's primary identification with the mother before entering into discrete subjectivity. She uses the Greek term chora to refer to a sense of being or presence that belongs to each person before he or she develops clear borders of his or her own individual identity. The chora is the subject's point of origin and the site of its dissolution. Kristeva also uses the term "semiotic chora" to highlight the extra-verbal way in which bodily energy is inscribed in language, such as in the rhythms and intonations of an infant who does not yet know how to use language symbolically; that is, through the use of symbols, grammar and syntax. ${ }^{13}$ As such, the human desire to make and listen to music can be seen to have its origin in that moment when the child begins to acquire a capacity for verbal communication. Later, we will see how the chora's uncanniness is inscribed in the visual iconography of drum ' $n$ ' bass via the fetishised "dark space" of the post-industrial city and in musical terms through the deep, low-frequency murmurs of its bass-lines.

\section{DARK City}

THE THEMATIC prominence of "darkness" within drum ' $n$ ' bass culture has been heavily informed by the post-industrial conditions of its development. Although not all drum ' $n$ ' bass tracks feature dystopian atmospheres, the continued popularity among participants of "dark" sub-genres like techstep ${ }^{14}$ points to the difficult social conditions that preceded the formation of the genre during the UK's deepest economic recession since the Second World War in the early 1990s, as well as to events such as the global economic downturn of 2008, as their consequences are played out in the lives of the working-class young people that form the music's core audience in London.

Examining the impact of deindustrialisation on East London, Anthony Giddens shows how the decline in shipbuilding and other related forms of industrial work have created a poor, undereducated and underemployed base of local residents, despite government policies since the 1980s to encourage private enterprise to play a key role in the regeneration 
of its inner city regions (2006: 917). For many young people, all-night dancing at clubs and raves in and around inner city areas like Hackney and Peckham offered a form of ritualised working-class sociality that had declined with the loss of thousands of local manufacturing jobs. Disused factories and warehouses were themselves occupied for the staging of drum ' $n$ ' bass events. In this way, urban spaces, which offered employment and social ties for working class people, were rendered "dark" before being reoccupied, often illegally, as leisure spaces.

By suggesting that "difficult and often painful experiences are integral to urban living", Kevin Robins and Frank Webster suggest that fatalism constitutes a main attitude to life in the post-industrial city (1999: 258). For many drum 'n' bass participants, the "difficult" conditions of urban living can generate a sense where locality is in fact inescapable destiny and where horizons of activity extend only as far as the boundaries of the "urban jungle", facilitating an intensified desire for instant gratification. This outlook permeates the foreboding ambience of early tracks like "Valley Of The Shadows" by Origin Unknown (1993), which places a female voice intoning "I felt that I was in this long dark tunnel" alongside a murmuring bass-line. During the early development of this burgeoning genre of up-tempo break-beat EDM (between 1992 and 1994), "jungle" and "drum 'n' bass" were being used synonymously with "darkcore" and "dark". In this context, the metropolis can be seen to constitute a form of subjective architecture; a "junglist" is someone who shows strong dedication and commitment to the "scene", thereby asserting his or her ability to survive in the "urban jungle".

Along with bass, the use of looped break-beats ${ }^{15}$ - a creative practice drum ' $n$ ' bass shares with US hip hop music - suggests the music's intimacy with urban space. A number of commentators have shown that hip hop has drawn part of its appeal from mysterious urban topographies enunciated by hip hop or "rap" lyrics. Drum ' $n$ ' bass similarly draws on the uncanniness of city life, as indicated by track titles like "Edge City" by Kubiks and Lomax (The Big Picture Part 3, 2006) and "Twisted City" by Dom and Keaton (Back For The Future, 2002). However, its largely instrumental musical framework makes it more difficult to ground the genre within a fixed space. Accelerated rhythmic flows are typically combined with abstract soundscapes, avoiding the essentialist assertions of Black cultural nationalism more commonly associated with US hip hop culture.

Alongside its use of break-beats, drum ' $n$ ' bass is informed by a myriad of African diasporic music styles, such as reggae, jazz, house and techno; the latter a mid-tempo form of EDM whose formation out of the post-industrial conditions of Detroit in the mid1980 s-together with its post-humanist aesthetic-are comparable with the conditions informing the development of drum ' $n$ ' bass a decade later. In addition, while initially occurring in the definable geographical space of post-industrial London, drum ' $n$ ' bass can be seen to articulate the unstable pathways between the metropolitan and the regional, the global and the local, as shown by the popularity of the sambass sub-genre, exported to the dance clubs and pop charts of the UK by Brazil's DJ Marky in the mid-2000s, or the Asian drum ' $n$ ' breaks scene, which draws on classical Indian music, bhangra and Bollywood film soundtracks. Thereby, the development of drum ' $n$ ' bass can be closely linked to the 
development in the 1990s of what Manuel Castells calls a "network society", in which the speed of communications is entwined with the growing importance of "informationalism" as the main source of economic productivity (2000: 17). The role of London as a global nodal point for accelerated flows of commerce, information and migration can be seen to be inscribed in those parts of the city which have benefited from the shift to the network society. Despite its largely working-class demographic and cultural links to reggae sound system culture-imported to the UK from Jamaica in the 1970s-its formal emphasis on speed marks a crucial divergence between drum ' $n$ ' bass and preceding EDM styles in the African diasporic continuum.

While the ability of drum ' $n$ ' bass to attract new audiences has arguably diminished since the peak of its popularity in the late 1990s, the regular staging of events at inner city social dance venues at the time of writing (July 2010) - together with its crashing out from specific points in the everyday urban landscape, such as car sound systems, workmen's vans and the earphones of teenage tube commuters' iPods-attests to its continued relevance to the lives of working-class young Londoners. Dezert Rat-a DJ for East London's long-running drum 'n' bass pirate radio station Kool FM-reinforces the connection between difficult material circumstances and the sonic structures of drum ' $n$ ' bass: "Everyone's rushing around in London. It's such a fast-changing, chaotic place.... [Drum 'n' bass] couldn't have come out of anywhere else". ${ }^{16}$ Angela McRobbie similarly claims that the "breakneck speed of [drum ' $n$ ' bass] describes the frenetic economic lifestyle of the musicians, producers and DJs" (1999: x), many of whom "exist at the far end of the social scale" (1999: 17). These suggestions of a link between the fast tempos of drum ' $n$ ' bass and the desire of its participants to mitigate the harmful social effects of cultural acceleration and the fast-changing needs of the post-industrial economy can be supported by Adrian C. North and David J. Hargreaves (2007), who show that regular listeners of up-tempo DJ-based styles tend to be based in cities and have the lowest level of access to financial resources among music consumers. The frenetic character of drum ' $n$ ' bass music seems to highlight its participants' prioritisation of instantaneous pleasures over the future rewards that can come with deferred gratification; given the chaos of life in the present, the future may never come to pass.

The interconnectedness between difficult economic circumstances and the preference of drum ' $n$ ' bass participants for fast and rhythmically "chaotic" music can be further illustrated by the findings of Robert J. Brym and Gabriel Rossman (2010). Brym and Rossman mapped the beats per minute of all the songs in the Billboard Hot 100 charts between 1955 and 2009 with Dow Jones Industrial Averages over the same period. Their results showed that periods of economic growth are associated with slower music while periods of economic recession or stasis are associated with faster music. Since these findings exclude the relatively small-scale business activity with which such styles are concerned, drawing deterministic conclusions about the preferences of members of a music-based youth subculture like drum ' $n$ ' bass from broad-based corporate data can be problematic. However, Brym and Rossman's research does point to a revealing link between musical taste and wider economic circumstances: faster beats correlate with periods of financial 
slowness. The specific socio-economic circumstances of inner city working-class youth in post-industrial London where drum ' $n$ ' bass initially developed in the early 1990s seems to support such a relationship between musical tempo and wider economic circumstances.

The visual iconography of drum ' $n$ ' bass culture reconstitutes the post-industrial city as a trope for the future as a period of inevitable decline. Such a fatalistic outlook is informed by the stratification of speed in a network society. Zygmunt Bauman (2006) goes even further than Castells in arguing that the increasing speed with which information is transmitted via information and communications technologies (ICTs) itself facilitates the inscription of social power. For Bauman, the transformation from "solid" to "liquid modernity" has accompanied the growth of a "nomadic and extraterritorial elite" that uses ICTs to generate "liquid capital" and a complex bureaucratic network to manage the lives of the "settled majority" (2006: 13). ${ }^{17}$ This imbalance of social power brought about by liquid capitalism has produced a scenario to rival the dystopian futures imagined by the great science fiction writers of the 20th century, a "dystopia made to the measure of liquid modernity-one fit to replace the fears recorded in Orwellian and Huxleyan-style nightmares" (2006: 15). "Dark" futures are frequently depicted in drum ' $n$ ' bass promotional material. In a flyer for the monthly club run by the Renegade Hardware record label (fig. 1), a post-industrial cityscape-signified by brightly lit skyscrapers and corporate buildings-is overlooked from the sky by the Renegade Hardware logo, characterised as a floating metallic monolith. These looming structures indicate the extent to which the speed of ICTs gives control over social and environmental changes in the city to those with the highest levels of cultural and economic capital. They also show how the technocultural framework from which speed emanates exerts a powerful fascination for the relatively immobile urban and working class audiences of drum ' $n$ ' bass, addressing the subjective impact of the flows and impulses of deindustrialisation, globalisation and the growing economic importance of ICTs relative to heavy industry and manual labour. The multiple, luminescent lines of vertically scrolling numbers constitute the popular image for both digital code-as depicted in Hollywood science fiction films such as $\mathrm{Pi}$ and The Matrix - and biological DNA code. This dual definition points to Jean Baudrillard's concept of genetic and digital code as a deterministic mode of biological and technological pre-programming in a condition of simulation (1994). For Baudrillard, the dynamics of representation depend on a series of conventional and seemingly absolute divisions between reality and representation, medium and message, subject and object. These differences are rendered equivalent to the extent that they are seen to be extensions of one code: "A single model, whose efficacy is immediate, simultaneously generates the message, the medium and the real" (1994: 82). As such, the code is hegemonic; it is the one substance that underpins a number of different modalities, and, as a result, all the different modalities are rendered fundamentally the same. 


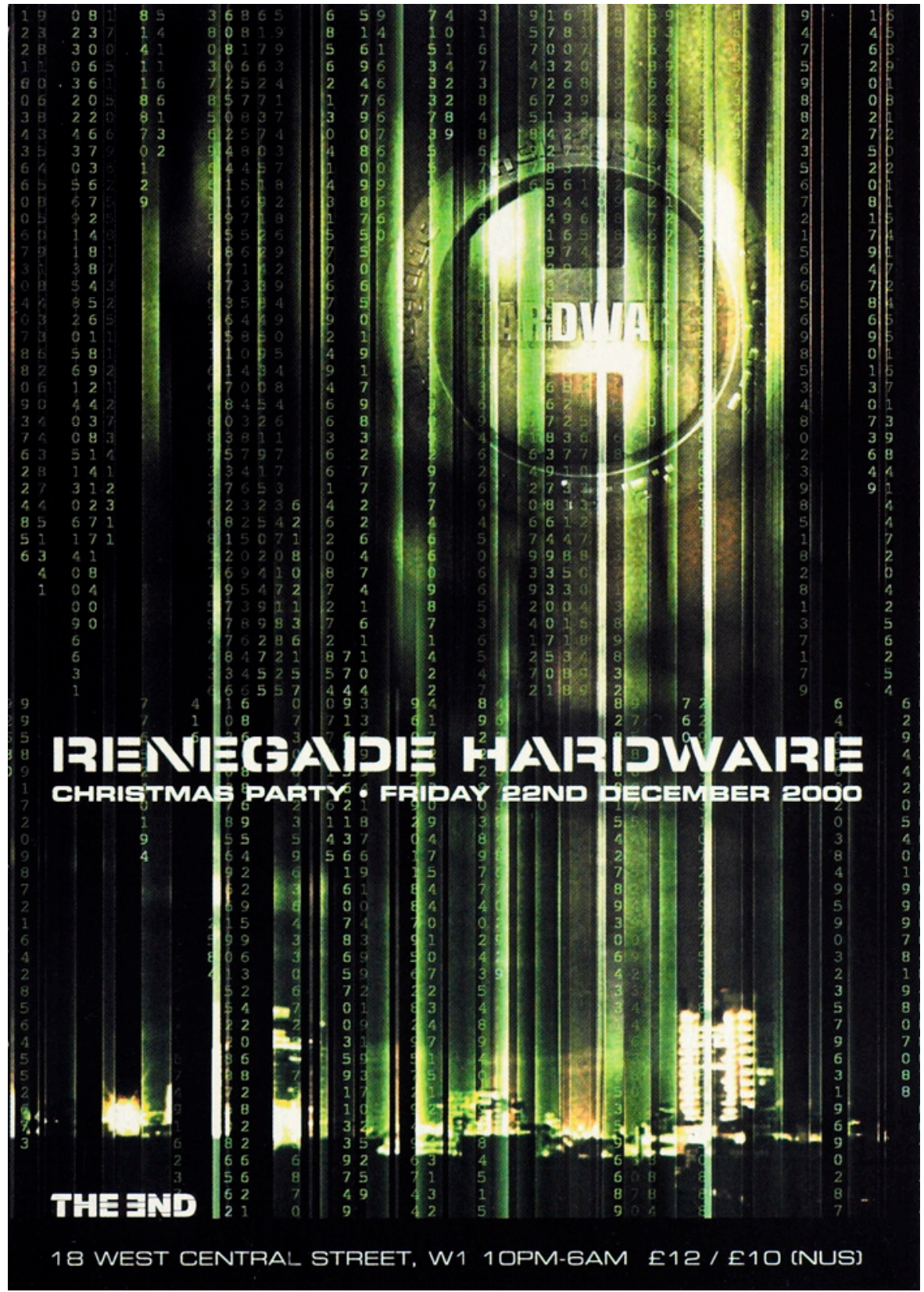

Figure 1: Flyer for Renegade Hardware club night at The End, London, December 2000.

Throughout drum ' $n$ ' bass culture, the "future" is marked by the subject's vulnerability to control by the code, where media technologies are also technologies of surveillance and social control. The hegemony of the code in the Renegade Hardware flyer is signified in terms of the extent to which all living and non-living activity in the post-industrial city is subject to its operation. As a medium of control-indicated by the monolith-the code is defined as immanent and all-powerful. Phillip Tagg's view that low sounds in Western 
culture tend to connote space, darkness and fear, while high sounds are linked to activity and vitality (2000: 173-9), can be used to illustrate the stratification of speed in the sonic structures of drum 'n' bass. Fast break-beats signify the imposition of speed from "on high". Conversely, drum ' $n$ ' bass bass-lines, which usually run at half the tempo of the break-beats, can be seen to convey a feeling of slowness and immobility "from below".

In the Renegade Hardware flyer, the code is reframed as the "renegade hardware" of accelerated information flows, whose effect is to negate the possibility of cultural resistance. Joost Van Loon claims that the increasing desire for speed in a "technological culture" has created an intensified urge for control: "Whilst being generated by a desire for speed and overcoming obstacles of time and space [communications technologies] have also engendered new forms of alienation" (2002: 153). Van Loon claims that an "assemblage of media technologies" has "started to pervade the military-industrial complex, large corporations, the state apparatuses, the culture industries and increasingly our private homes" (2002: 152). Amidst the "speed and irreversibility" of this assemblage, media technologies have surpassed "our ability to master and control it and subject it to our programming of the future" (2002: 152). In these senses, the promotional context of the flyer and the image it contains allows for three interpretations linking the code, urban space and an attitude of fatalism towards the future. Firstly, the hegemonic power of the code is linked to the cachet of the Renegade Hardware label in drum 'n' bass culture. Secondly, technology itself as the medium of power in the post-industrial city has become "renegade" in the sense that it has been appropriated by those who are routinely oppressed, exploited and rendered surplus to requirements. Thirdly, by listening and dancing to the club's main soundtrack of techstep drum ' $n$ ' bass, the subject can adopt a post-humanist identity where cyberspace has surpassed the real space of the city as the dominant site of power in a post-industrial society.

The acquisition of post-humanist identity in a condition dominated by the code acts as a key indicator of drum ' $n$ ' bass culture's foregrounding of dark urban futures. In relation to science fiction film, Scott Bukatman argues that:

In cyberspace, the density of the inner city became an analogy for the dispersed matrices of information circulation and overload, while cyberspace itself presented an urbanism stripped to its kinetic and monumental essentials. Cyberspace exaggerated the disorienting vertigo of the city, but it also summoned a powerful controlling gaze (2002: 47-8).

A similar anxiety of the inner city as the main site of "information circulation and overload" concerns the programming of human behaviour in cyberspace. In this scenario, the urbanite is trapped "inside the machine", to borrow the title of an album by Bad Company (see fig. 2), suggesting that resistance to a post-industrial society dominated by global corporate power should be concerned with disrupting the networks through which its control is directed from within cyberspace. 

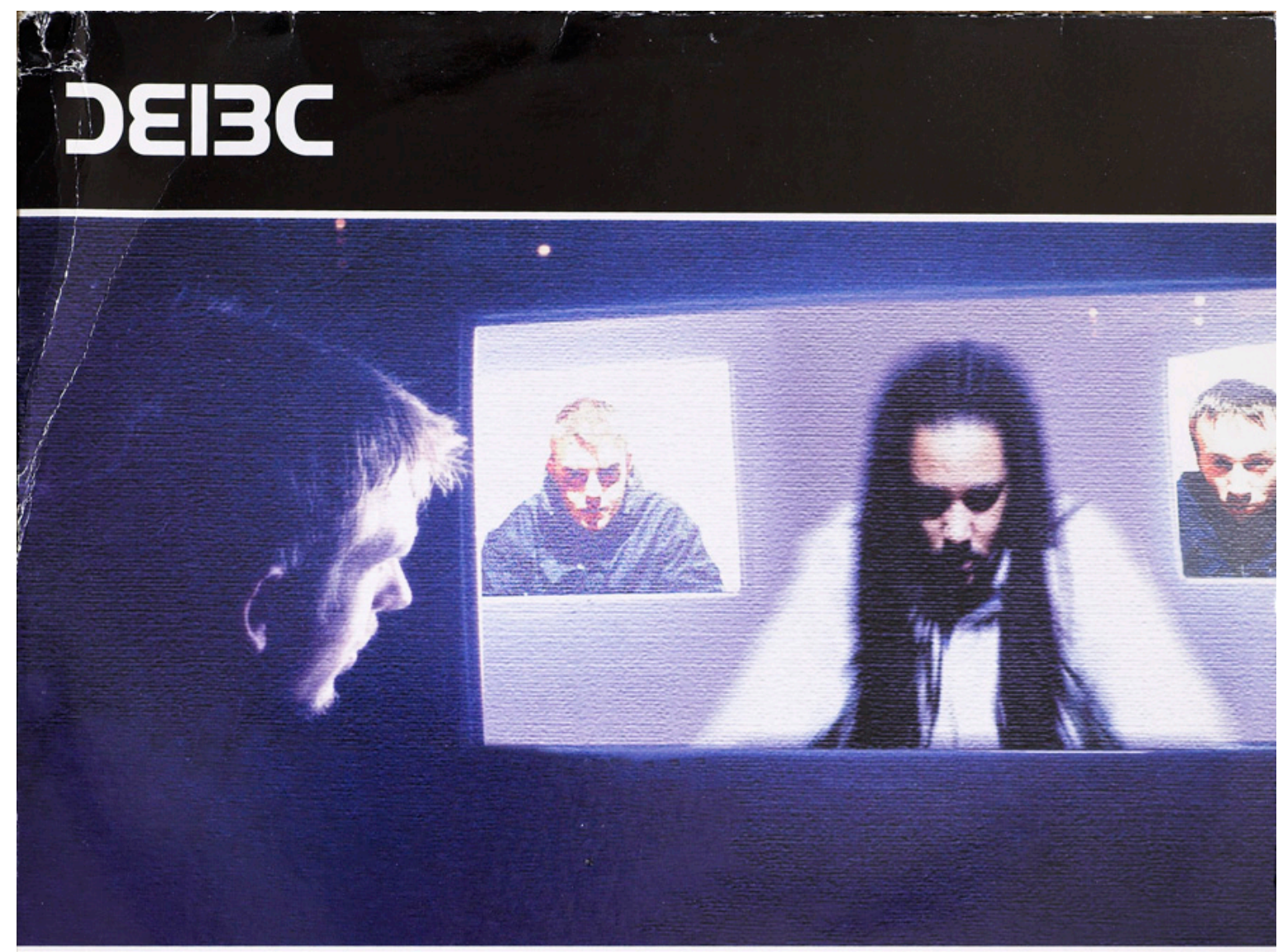

\section{LSEIDE THE IIACHINE}

Figure 2: Inside The Machine By BAD Company (2000).

In his sleeve notes for The Prototype Years LP (1997), DJ and producer Grooverider rhetorically asked, "It's Blade Runner business, innit?" This question is intended to convey the album's thematic affinity with the science fiction film based in a future Los Angeles characterised by social and subjective fragmentation. A number of the album's track titles make explicit references to experiences of urban uncanniness, such as "City Lights" by Lemon D and "Subway" by Ed Rush. In terms of musical content, their bleak, sinister soundscapes and heavy bass construct the post-industrial city as dense, confusing and overpowering; it is fetishised as a dark space. In particular, the "darkness" often ascribed to 
bass by participants points to Homi K. Bhabha's suggestion that, in wider cultural discourse, "[d]arkness signifies both birth and death; it is in all cases a desire to return to the fullness of the mother, a desire for an unbroken and undifferentiated line or origin" (2004: 68). Similarly, Dezert Rat says, "bass is something you feel deep inside, you almost can't explain it. ... It's like you're connecting with Mother Nature, but it's dark at the same time". This framing of bass as having origins that are both maternal ("you're connecting with Mother Nature") and uncanny ("you almost can't explain it") can be linked to Mary Ann Doane's discussion of the Freudian description of female sexuality as a "dark continent" (1991: 20912). For Doane, the "dark continent trope is hence invoked in the context of a return to the motifs of castration, lack, and envy" (1991: 210). In other words, a sense of the uncanny is connected to desire through the signifying space of the mother's body. According to Jacques Lacan (1977), desire is defined by absence; it is an appeal to receive from the other that which it lacks, forming out of the "darkness" that precedes selfhood. In drum 'n' bass culture, the darkness that characterises the unhomeliness of the urban uncanny is seemingly combined with the primary space of the mother's body as fetish, thereby normalising the "dark city" as a homely space.

\section{BASS IS MATERNAL}

THE SONIC DOMINANCE of bass can be considered a trace of crucial West Indian musical and cultural practices. For Dick Hebdige, the bass-line provides "the basic background throb of reggae's heartbeat" (1987: 82). Within the history of reggae's opposition to institutional and colonial authority, such a "heartbeat" has arguably evolved into a post-colonial signifier of political resistance (Gilroy 2002). In particular, the importing of Jamaica's reggae sound systems to English cities in the mid-1970s helped to foster a sense of solidarity between "blacks" and "whites" on the basis of shared working-class experiences (Hebdige 1987). This trace of resistance continues to resonate in the lexicology and sonic spaces of UK EDM. In this way, drum ' $n$ ' bass articulates the material reality of Paul Gilroy's (1993) model of the Black Atlantic that traces a continual cultural flow between the United States, the Caribbean, and the United Kingdom. References to "rebel bass" or the Dread Bass by Dead Dread (1994) signify the defiant sonority of bass-heavy music within Black Atlantic cultural discourse. Julian Henriques goes as far as to suggest that reggae sound system culture supplants vision as the "dominant sensory modality" of the post-Enlightenment West (2003: 464). For Henriques, bass frequencies galvanise participants into a complete whole within sonic space: "sound is everywhere, hardly even making the dualistic division between here and there" (2003: 459). In this context, low frequencies can also seem to animate the boundary-less bliss the child felt in the womb, its "original" home. Ultrasound studies have shown that only the lowest sounds in the frequency spectrum of hearing audible to humans are the first to be heard by prenatal infants with normal inner ear development (Gerhardt and Abrams 1996). ${ }^{11}$ These suggest that primal memories of low-frequency sound are instilled while the infant is still in the womb, reinforcing a sense that, to use the title of an album by the Bristol-based reggae and drum 'n' bass group Smith and Mighty, Bass is 
Maternal (1995). Hillegonda Rietveld argues that the womb-like environment of the dance floor is re-imagined as a return to the mother's body where the dancer is surrounded by the sound of her mechanical heartbeat (1998: 148-9). ${ }^{12}$ In a biological sense, low sounds also register powerfully in the lower regions of the body, such as the stomach where the child was nourished by the umbilical cord. Thereby, it is arguably the mother's heartbeat-heard as low-pitched murmuring and throbbing from within her body-that enables bass to convey a sense of jouissance ${ }^{13}$ on the dance floor, while allowing it to be read as an articulation of the post-colonial character of Black Atlantic culture. In this way, bass forms the sonic basis for boundary-less presence linking the cultural and geographic nodes of the African diaspora, where, as argued by Iain Chambers in reference to the work of poet Linton Kwesi Johnson, "bass history is a hurting black story" (1985: 161).

Roland Barthes (1977) draws heavily on Kristeva's notion of the chora to show how richly textured sound can offer access to unconscious drives as they organise and disrupt the subject and the experience of its body. For Barthes, the role of sonic timbre, or "grain", is to open up a pathway to the chora: "grain is ... the materiality of the body speaking its mother tongue; perhaps the letter, almost certainly significance ... the space when significations germinate 'from within language and in its very materiality"' (1977: 182). It can be argued that all richly-textured sounds have the capacity to stimulate a sense of non-differentiation with the mother. Bass can be considered especially potent in this regard; its heavy sonority at hot, dark and crowded drum ' $n$ ' bass dance clubs (see fig. 3) can seem to summon primal memories of being in the womb. In addition, the frequent use by participants of fatalistic terminology like "dark" to describe bass indicates that the music is heavily informed by a Western patriarchal discourse. Barbara Creed (1990) refers to the chora to claim that motherhood in a mythical form is present as the void, death and darkness in all texts that convey a sense of horror. On the dark drum ' $n$ ' bass dance floor, bass seems to have a maternal quality; she is "darkness" - the "Big Bad Bass", as one event is called (see fig. 4) —and hence can be linked to the horror evoked by the chora's threat of dissolution (Creed 1990). Though blissful, regression to a womb-like, boundary-less state of jouissance initiated by the grain of low-frequency sound can also be accompanied by painful throes, given that, for Kristeva, the chora is the site of the subject's dissolution.

Barbara Bradby's claim of an "equation between rhythm, bass and masculinity" (1993: 168) can be supported by existing cultural and critical research into the changing meaning of male identity in a post-industrial context. ${ }^{14}$ In this regard, it might also be useful to examine the "hurting" quality of bass in terms of what Yvonne Tasker refers to as a crisis of masculinity linked to declining interactions with the heavy technologies of industrial production. For Tasker, deindustrialisation has brought about a crisis of meaning for male bodies that were subjectively fortified by the need for physical strength and dexterity in the use of industrial machinery (2004: 110). ${ }^{15}$ She claims that, in the shift from an industrial society of production to a post-industrial society of consumption, technological development has been complicit in the "denaturalising of the supposed naturalness of male identity" (2004: 110). The "denaturalisation" of the maleness of technological culture now characterised 
by cybernetics and the code is constructed by drum ' $n$ ' bass culture in terms of feminised hi-tech imagery drawn from popular science fiction film. For Doane, the displacement of male labour by technology in post-industrial society is the basis for what she describes as the "technological fetishism" of science fiction imagery (1990: 174). Such fetishism involves "issues of the maternal, reproduction, representation and history" (1990: 174). In Alien, for example, the alien is a "monstrous mother-machine, incessantly manufacturing eggs in an awesome excess of reproduction" (1990: 174). In patriarchal discourse, maternal excess is managed through a feminisation of technology as fetish (Kember 1995). In sonic terms, the womb-like "darkness" of bass—a sonic space DJ Dezert Rat linked to "Mother Nature" - can be seen to carry a particular significance for the largely male and working class audience of drum ' $n$ ' bass; the power of technological reproduction is linked to the female body's system of biological reproduction. In the originating and birthing space of the womb, the subject can acquire a sense of reproductive power while itself seeming to be reproducible. This feeling of reproducibility is linked to rebirthing, as suggested by Kool FM DJ Lace's comments that a "good bass-line makes you feel like you're coming alive". ${ }^{16}$ In this sense, the fetishisation of the maternal body within the sonic space of bass can seem to contain the denaturalisation of male identity's relationship with technology as a result of deindustrialisation, even though feelings of power produced in and through bass are framed in terms of female identity and the mother's body.

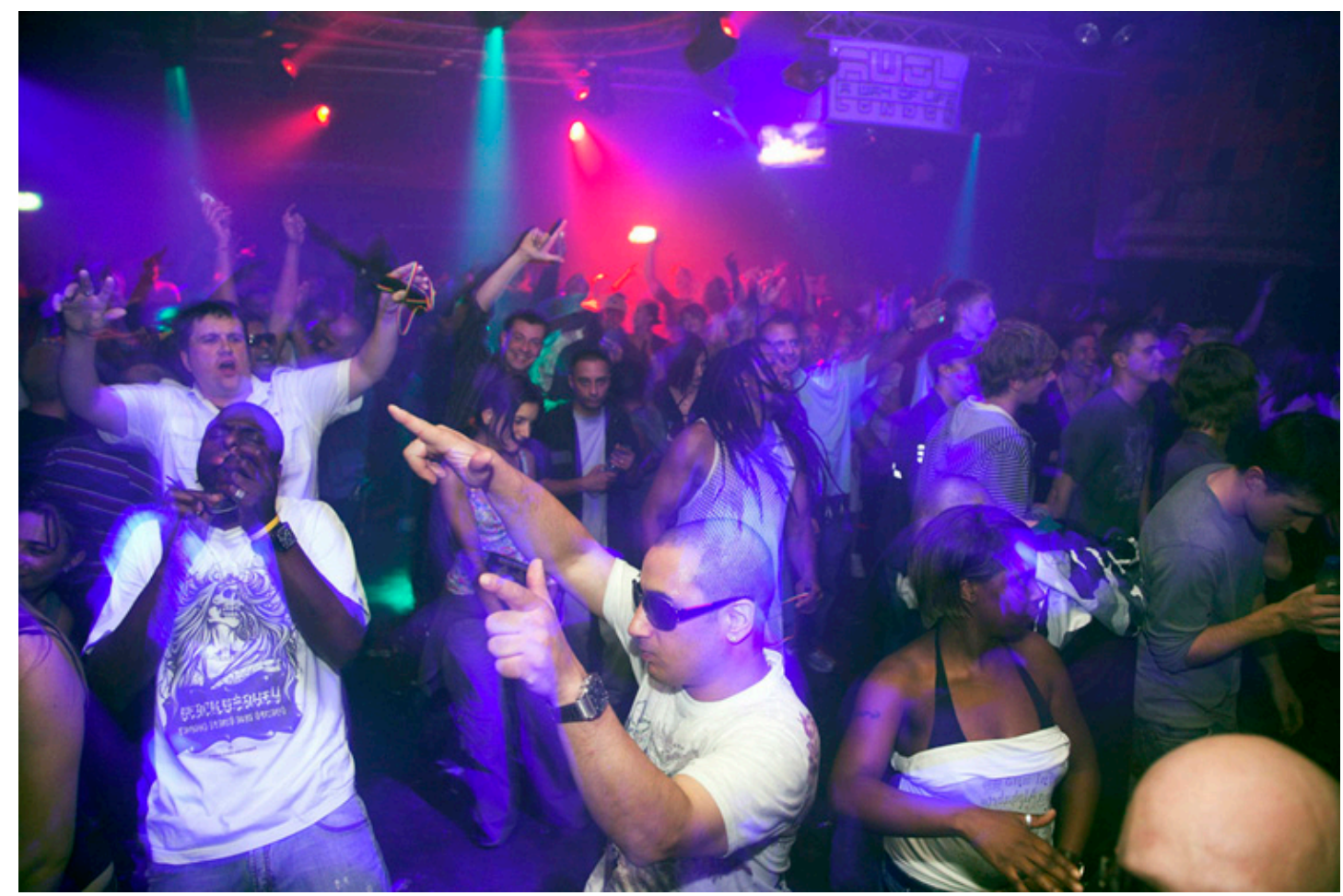

Figure 3: The dance floor at the World's longest RUNNing drum 'N' bass Club, A.W.O.L., March 2007. РhOto BY JAMES BURNS: <JAMES.RAWIMAGES@GMAIL.COM> 


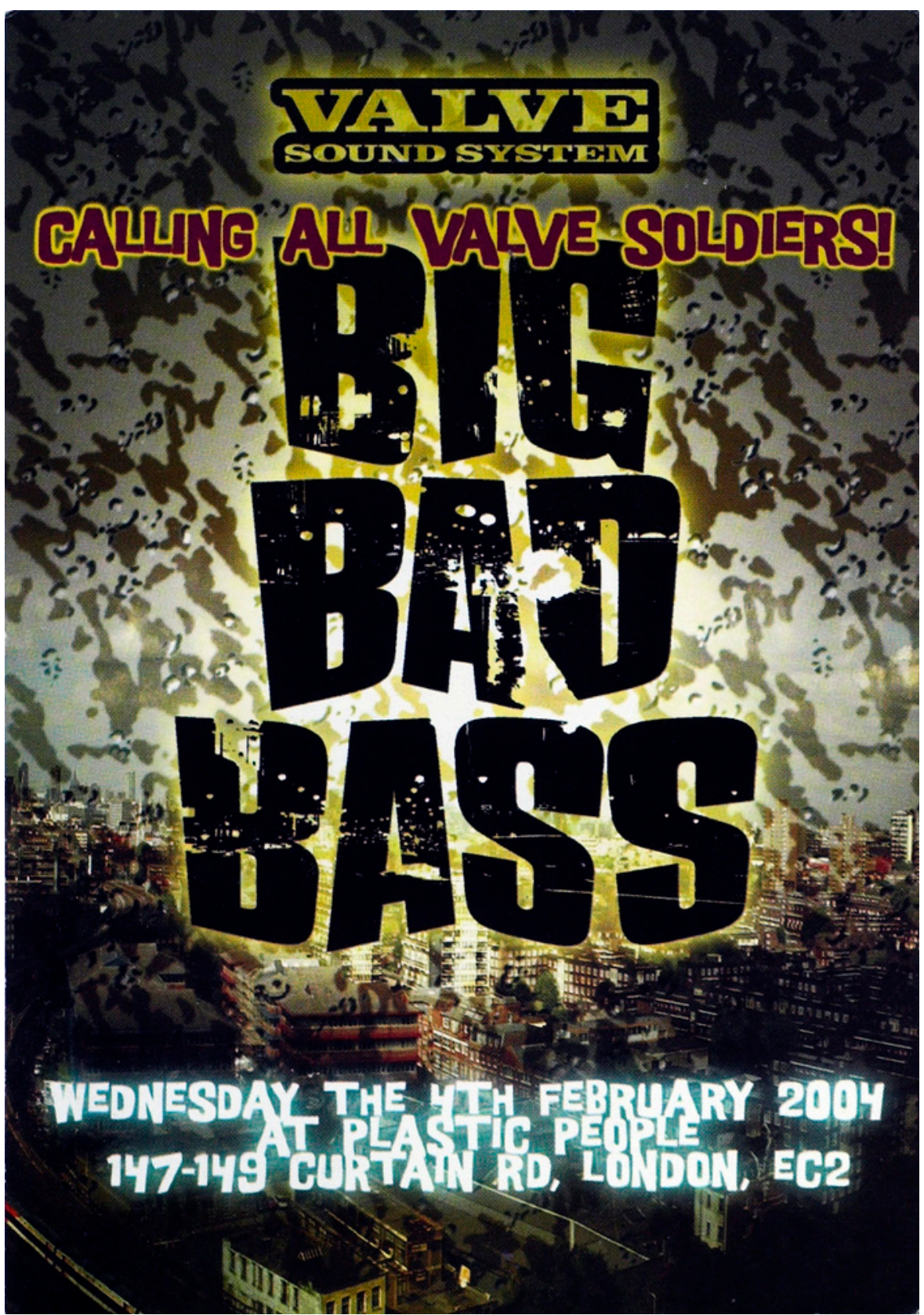

Figure 4: Flyer for the Valve sound-system's Big Bad Bass event at Plastic People, February 2004.

Throughout the visual iconography of drum ' $\mathrm{n}$ ' bass, technological fetishisation often takes the form of a sexualised female cyborg, or "cybernetic organism" (see fig. 5). This fetishisation can be seen to belong to a long history of the eroticisation of technology as a response by male labour and cultural power to the threat of machines. For example, Andreas Huyssen describes the robot Maria in Fritz Lang's Metropolis as the "vamp in the 
machine", designed to seduce the insurgent proletariat into submission (Huyssen 1982). Similarly, Rietveld shows that Maria's purpose is to "normalise the male experience of new technology" (2004: 56). Huyssen argues that the "fears and perceptual anxieties emanating from ever more powerful machines are recast and reconstituted in terms of the fear of female sexuality, reflecting, in the Freudian account, the male's castration anxiety" (1982: 226). Thereby, technological fetishisation enables the social "castration" of male labour power to be mitigated by investing technological culture with the "naturalness" of female sexuality. ${ }^{17}$ In drum 'n' bass culture, technology is also often fetishised in terms of the female body's urban uncanniness; she is imagined as a reproductive machine that has castrated male labour from its "natural" position of power in industrial society. On dance event flyers and record sleeves, mechanical vamps are often situated in post-apocalyptic imagery of the city derived from dystopian science fiction films like Blade Runner. In this way, she briefly resolves male castration anxiety-both in the immediate, post-industrial context and in the deeper, psychological sense-through a return to the fullness of the chora as the original "home", thereby seeming to "complete" the mother's own castrated body.

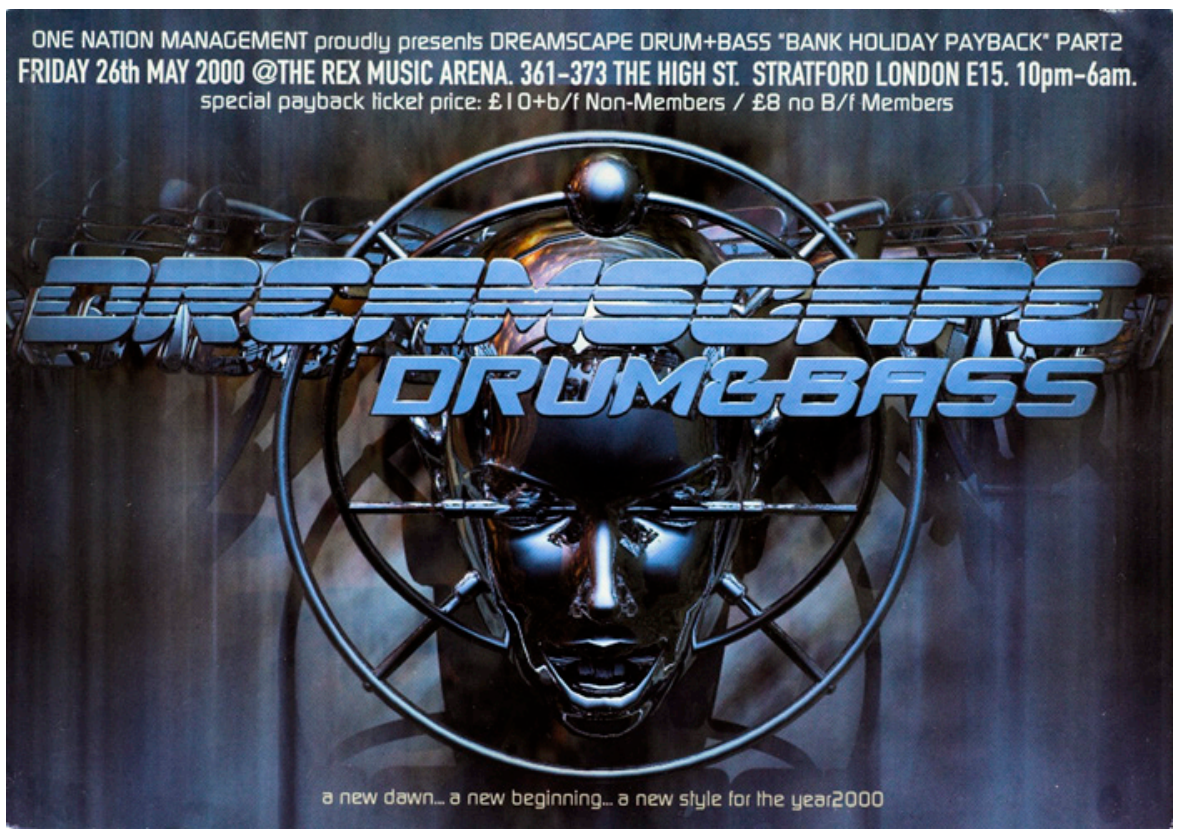

Figure 5: A "VAmp in the machine" on a flyer for a Dreamscape raVe, May 2000.

This article has proposed that bass functions as a sonic inscription of the urban uncanny in electronic dance music, especially in drum ' $n$ ' bass, where feelings of uncanniness are brought about by the uncontrollable speed of life for those who live and grow up in London, its place of origin. The pace of socio-economic change brought about by deindustrialisation and the displacement of traditional male labour by cybernetics and information and communications technologies since the 1980s has facilitated a contextualisation throughout drum ' $n$ ' bass 
culture of the post-industrial city as a "dark" space that is both home and unhomely. The "darkness" of low-frequency sound as described by its mainly working class participants develops out of its framing within a general fatalistic attitude to life in the "urban jungle". Additionally, the embodied materiality in its sonority and loudness on the drum 'n' bass dance floor seems to stimulate primal memories of the original home, the womb. The womb is both a place of safety and danger, a duality that is combined with images of the "dark city" in the lexicology and visual iconography of drum 'n' bass culture. In a wider sense, the fetishisation of both the post-industrial city and technology involves their reconstitution as inescapable destiny - a destiny that can be linked to Kristeva's notion of the chora as a space of both birth and dissolution-and female sexuality respectively. This feminisation points to a desire on the part of its largely male and working-class participant base to normalise the uncanniness of seemingly uncontrollable techno-social changes in the urban landscape. While revealing the function of drum ' $n$ ' bass cultural production within a patriarchal discourse, it also illustrates the ability of exciting, if largely hidden, creative spaces to be fostered from the most precarious post-industrial circumstances.

\section{ENDNOTES}

1 This paper is drawn from the author's $\mathrm{PhD}$ research project into the politics of speed in drum 'n' bass culture (see Author Biography). Participant comments referred to in this paper were taken from interviews conducted with DJs and producers, along with club and rave audience members during this time.

2 I mainly use "drum ' $n$ ' bass" rather than "jungle" - the term with which it is used interchangeably_as "drum ' $n$ ' bass" is more frequently used by participants at the time of writing (July 2010).

3 Drum ' $n$ ' bass is a form of electronic dance music based on prominent bass sounds and breakbeats, or digitally sampled (recorded from existing musical recordings), accelerated and "looped" (repeated) rhythmic patterns. The bass-lines typically run at half the speed of the break-beats. Typically, drum ' $n$ ' bass tracks have tempos in excess of 150 BPM, often reaching between 170 and $180 \mathrm{BPM}$. To provide some contextualisation of the speed of drum ' $\mathrm{n}$ ' bass music, it is useful to note that most recordings from the genre are around 100 BPM faster than the African-American soul and funk records of the 1960s and 1970s from which break-beats are often sampled.

4 According to Simon Reynolds, "The speed aspect [of jungle/drum 'n' bass] is crucial. Scene insiders offer platitudes like 'jungle is a feeling'. But if you need a definition, the music's core is the accelerated, chopped-up break-beat rhythms that create ... a sound-picture of social disintegration and instability" (1998: 239).

5 Vidler's use of the uncanny can also be linked to another psychoanalytic concept, that of projection, where that which appears to manifest itself externally or from the outside can be the return of concealed material; manifestations drawn from a repository of repressed desires or memories.

6 According to Kristeva, the semiotic chora signifies that which is below the surface of the speaking being: "Discrete quantities of energy move through the body of the subject who is not yet constituted as such and, in the course of his development, they are arranged according to the 
various constraints imposed on this body—always already involved in a semiotic process-by family and social structures. In this way the drives, which are 'energy' charges as well as 'psychical' marks, articulate what we call a chora: a non-expressive totality formed by the drives and their stases in a motility that is as full of movement as it is regulated" (1984: 25). By "motile", Kristeva means the quality of exhibiting or being capable of spontaneous movement.

7 Techstep is a sub-genre of drum 'n' bass characterised by harsh noise, tonal dissonance and a discourse of sonic violence. Pioneered in the mid-1990s by producers Ed Rush, DJ Trace and Nico Sykes at Sykes' West London-based No-U-Turn record label, its defining feature is the distorted bass sound, achieved by feeding the pre-recorded bass notes into music equipment effects settings like distortion and overdrive. Techstep incorporates within the drum 'n' bass paradigm aggressive elements and a dystopian science fiction aesthetic.

8 Tricia Rose (1994) shows how hip hop culture developed in the late-1970s as a response by young African-Americans to the social and subjective effects of deindustrialisation, such as high levels of crime, unemployment, as well as being a reaction to a longer legacy of institutionalised racism in the United States. She highlights how traditional African diasporic impulses of rupture, repetition and circularity have informed hip hop's break-beat aesthetic (1994: 67-74).

9 DJ Dezert Rat, interview with the author (The End nightclub, Central London), 19 September 2007.

10 It is notable that the "liquidity" Bauman identifies as a key feature of light capitalism is also linked to the permeation in drum ' $n$ ' bass musical and linguistic discourses of liquidity, in the form of the sub-genre "liquid funk", and in the colloquial use of the term "liquid", meaning "progress" or "positive movement".

11 According to Kenneth J. Gerhardt and Robert M. Abrams: "Low-frequency sound energy easily penetrates to the fetal head, less than $5 \mathrm{~dB}$ attenuation for frequencies below $500 \mathrm{~Hz}$, whereas higher frequencies are attenuated by up to 20 to $30 \mathrm{~dB}$. The sound energy in amniotic fluid stimulates fetal hearing through a bone conduction route rather than through the external and middle ear systems. During passage through the bones of the skull, sound energy is slightly diminished for frequencies less than $250 \mathrm{~Hz}$ (10 to $20 \mathrm{~dB}$ ), yet significantly reduced for frequencies from 500 to $2,000 \mathrm{~Hz}(40$ to $50 \mathrm{~dB})$ " (1996: 11).

12 It is useful to note that Rietveld is drawing on Richard Middleton's argument that music can be considered a "primary semiotic practice": "The initial connotations of sound-structures (the origins of which may go back beyond the repetitive 'coos' of the mother even into the womb: the (equally repetitive) sound/feel of maternal breathing and heartbeat) are prior to any emergence of a subject, locating itself in opposition to any external reality" (1990: 288).

13 Central to the poststructuralist theories of Roland Barthes (1977) and Julia Kristeva (1984), jouissance refers to a type of extraordinary sensation which derives from the moment before the human child leaves its comfortable state of bliss associated with still having access to the mother's breast.

14 While some female DJs and producers like Kemistry and DJ Rap have carved out successful drum ' $n$ ' bass careers, the style's cultural production base remains heavily male in character, thereby resembling the gender balance within most other EDM genres and the music industry as a whole. However, in the area of consumption, specifically on the drum 'n' bass dance floor, 
female membership is more strongly represented.

15 As Colin Harbury and Richard Lipsey highlight, "the occupational structure in Britain has been changing considerably in recent years.... [W] omen outnumber men as clerks, secretaries, nurses, teachers, shop assistants, and are increasingly taking managerial and administrative jobs. ... Technological advance has led to the replacement of an increasing number of manual jobs by machines; and growth of the service sector in the economy and professionalism of more and more skills has taken place" (1993: 113).

16 DJ Lace, interview with the author (The End nightclub, Central London), 19 September 2007. 17 In this regard, my findings differ from those of Maria Pini, who uses the cyborg as a metaphor for the "ecstatic unfixing" of traditional gender boundaries in rave culture (2001: 170). Pini argues that the embodiment of technology brought about by dancing to EDM amounts to a deconstruction of the "Enlightenment equation of women with nature" (2001: 170). In this vein, Pini's otherwise excellent research seems to overlook the visual culture involved in the promotion of EDM.

\section{REFERENCES}

Barthes, Roland. 1977. “The Grain of the Voice”. In Image-Music-Text. Trans. Stephen Heath, 179-89. London: Fontana.

Baudrillard, Jean. 1994 [1981]. Simulacra and Simulation. Trans. Sheila Faria Glaser. Ann Arbor: University of Michigan Press.

Bauman, Zygmunt. 2006. Liquid Modernity. London: Polity.

Bhabha, Homi K. 2004. “The 'Other' Question”. In A Critical and Cultural Theory Reader, eds. Anthony Easthope and Kate McGowan, 62-9. Toronto: Toronto University Press.

Bradby, Barbara. 1993. "Sampling Sexuality: Gender, Technology and the Body in Dance Music". Popular Music 12(2): 155-76.

Brym, Robert J. and Gabriel Rossman. 2010. "How the Stock Market Influences the Hot 100 Billboard Charts". Darwin vs The Machine. 22 October: <http://www. darwinversusthemachine.com/2010/10/how-the-stock-market-influences-the-hot-100billboard-charts/> (accessed 8 February 2011).

Bukatman, Scott. 2002 [1990]. Terminal Identity: The Virtual Subject in Postmodern Science Fiction. Durham: Duke University Press.

Castells, Manuel. 2000. The Information Age: Economy, Society and Culture. Vol. 1: The Rise of the Network Society. Oxford: Blackwell.

Chambers, Iain. 1985. Urban Rhythms: Pop Music and Popular Culture. Basingstoke: Macmillan.

Creed, Barbara. 1990. "Alien and the Monstrous Feminine". In Alien Zone: Cultural Theory and Contemporary Science Fiction Cinema, ed. Annette Kuhn, 128-42. London: Verso.

Doane, Mary Ann. 1991. Femmes Fatales: Feminism, Film Theory, Psychoanalysis. London: Routledge.

Donald, James. 1995. “The City, the Cinema, Modern Spaces”. In Visual Culture, ed. Chris Jencks, 77-95. London: Routledge.

Freud, Sigmund. 2001 [1955]. The Standard Edition of the Complete Psychological Works of Sigmund Freud: Vol. 17 (1917-1919); An Infantile Neurosis and Other Works. Trans. James Strachey. London: Vintage. 
Gerhardt, Kenneth J. and Robert M. Abrams. 1996. "Fetal Hearing: Characterization of the Stimulus and Response”. Seminars in Perinatology 20(1): 11-20.

Giddens, Anthony. 2006. Sociology. Cambridge: Polity.

Gilroy, Paul. 1993. The Black Atlantic: Modernity and Double Consciousness. London: Verso.

- - 2002 [1987]. There Ain't No Black in the Union Jack. London: Routledge.

Gracyk, Theodor. 1996. Rhythm and Noise: An Aesthetics of Rock, London: I. B. Tauris.

Harbury, Colin and Richard G. Lipsey. 1993. An Introduction to the UK Economy. 4th rev. ed. Oxford: Wiley-Blackwell.

Hebdige, Dick. 1987. Cut 'n' Mix: Culture, Identity and Caribbean Music. London: Comedia.

Henriques, Julian. 2003. "Sonic Dominance and the Reggae Sound System Session”. In The Auditory Culture Reader, eds. Michael Bull and Les Back, 451-80. Oxford: Berg.

Huyssen, Andreas. 1982. “The Vamp and the Machine: Technology and Sexuality in Fritz Lang's Metropolis”. New German Critique 24/25(1): 221-37.

-_- 1986. After the Great Divide: Modernism, Mass Culture, Postmodernism. Bloomington: Indiana University Press.

Kember, Sarah. 1995. “Medicine’s New Vision”. In The Photographic Image in Digital Culture, ed. Martin Lister, 95-114. London: Routledge.

Kristeva, Julia. 1980. Desire in Language. Trans. Leon S. Roudiez. New York: Columbia University Press.

_- - 1984. Revolution in Poetic Language. Trans. Leon. S. Roudiez. New York: Columbia University Press.

Lacan, Jacques. 1977 [1949]. Écrits: A Selection. Trans. Alan Sheridan. London: Tavistock.

McRobbie. Angela. 1999. In the Culture Industry: Art, Fashion and Popular Music. London: Routledge.

Middleton, Richard. 1990. Studying Popular Music. Birmingham: Open University Press.

North, Adrian C. and David J. Hargreaves. 2007. "Lifestyle Correlates of Musical Preference. 2:

Media, Leisure, Time and Music”. Psychology of Music 35(2): 179-200.

Pini, Maria. 2001. Club Cultures and Female Subjectivity: From Home to House. London: Palgrave.

Reynolds, Simon. 1998. Energy Flash: A Journey Through Rave Music and Dance Culture.

London: Picador.

Rietveld, Hillegonda. 1998. This is Our House: House Music, Cultural Spaces and Technologies. Aldershot: Ashgate.

-__. 2004. "Ephemeral Spirit: Sacrificial Cyborg and Communal Soul". In Rave Culture and Religion, ed. Graham St John, 46-61. London: Routledge.

Robins, Kevin and Frank Webster. 1999. Times of the Technoculture: From the Information Age to the Virtual Life. London: Routledge.

Rose, Tricia. 1994. Black Noise: Rap Music and Black Culture in Contemporary America. Middletown: Wesleyan University Press.

Tagg, Philip. 2000 [1979]. Kojak: Fifty Seconds of Television Music. New York: Mass Media Music Scholars' Press, Inc.

Tasker, Yvonne. 2004 [1993]. Spectacular Bodies: Gender, Genre, and the Action Cinema. London: Routledge. 
Thornton, Sarah. 1995. Club Cultures: Music, Media and Subcultural Capital. London: Polity. Toop, David. 1995. "Metal Guru”. The Face, August: 90-95.

Van Loon, Joost. 2002. Risk and Technological Culture: Towards a Sociology of Virulence. London: Routledge.

Vidler, Anthony. 1992. The Architectural Uncanny: Essays in the Modern Unhomely. Cambridge, Mass.: MIT Press.

\section{DISCOGRAPHY}

Adam F. 1996. Metropolis. Metalheadz (12-inch): METH 023. <http://www.discogs.com/Adam-F-Metropolis-Mother-Earth/release/5560>

Bad Company. 2000. Inside The Machine. BC Recordings (12-inch): VD BCRLP 001. <http://www.discogs.com/BC-Inside-The-Machine/release/1475>

Dom and Keaton. 2002. Back For The Future. Dom and Roland. Moving Shadow (CD): ASHADOW 28 CD. <http://www.discogs.com/Dom-Roland-Back-For-The-Future/ release $/ 35728>$

Dead Dread. 1994. Dread Bass. Moving Shadow (12-inch): SHADOW 50. <http://www.discogs.com/Dead-Dred-Dred-Bass/release/6341>

Origin Unknown. 1993. Valley Of The Shadows. Ram Records (12-inch): RAMM 004. <http://www.discogs.com/Origin-Unknown-The-Touch-Valley-Of-The-Shadows/ release/17714>

Smith and Mighty. 1995. Bass Is Maternal. More Rockers (12-inch): ZLPKR002. <http://www.discogs.com/Smith-Mighty-Bass-Is-Maternal/release/794319>

Various Artists. 1997. Grooverider Presents The Prototype Years. Sony (12-inch): 4872191. <http://www.discogs.com/Grooverider-The-Prototype-Years/release/24448>

Various Artists. 2006. The Big Picture Part 3. Liquid V (12-inch): LQD 017. $<$ http://www.discogs.com/Various-Liquid-V-Club-Sessions-Vol-2-The-Big-Picture-EP-Part-3/ release $/ 789051>$

\section{FILMOGRAPHY}

Aronovsky, David. 1998. Pi. USA: Artisan Entertainment. < http://www.imdb.com/title/tt0138704/>

Cameron, James. 1986. Alien. USA: Twentieth Century Fox. <http://www.imdb.com/title/tt0090605/>

Lang, Fritz. 1926. Metropolis. Germany: Universum Film AG. <http://www.imdb.com/title/tt0017136/>

Scott, Ridley. 1982. Blade Runner. USA: Warner Bros. <http://www.imdb.com/title/tt0083658/>

Wachowski, Andrew and Wachowski, Larry. 1999. The Matrix. USA: Warner Bros. < http://www.imdb.com/title/tt0133093/> 